\title{
Liothyronine and levothyroxine prescribing in England: A comprehensive survey and evaluation
}

\author{
Mike Stedman $^{1}$ (D) | Peter Taylor ${ }^{2}$ | Lakdasa Premawardhana ${ }^{2}$ | Onyebuchi Okosieme ${ }^{2}$ | \\ Colin Dayan $^{2}$ | Adrian H. Heald ${ }^{3,4}$ (D)
}

${ }^{1}$ Res Consortium, Andover, UK

${ }^{2}$ Thyroid Research Group, Systems Immunity Research Institute, Cardiff University School of Medicine, Cardiff, UK

${ }^{3}$ The School of Medicine, Manchester Academic Health Sciences Centre, University of Manchester, Manchester, UK

${ }^{4}$ Department of Endocrinology and

Diabetes, Salford Royal Hospital, Salford, UK

\section{Correspondence}

Adrian H. Heald, Department of

Endocrinology and Diabetes, Salford Royal

Hospital, Salford, UK.

Email: adrian.heald@manchester.ac.uk

\begin{abstract}
Introduction: The approach to thyroid hormone replacement varies across centres, but the extent and determinants of variation is unclear. We evaluated geographical variation in levothyroxine (LT4) and liothyronine (LT3) prescribing across General Practices in England and analysed the relationship of prescribing patterns to clinical and socioeconomic factors.

Methods: Data was downloaded from the NHS monthly General Practice Prescribing Data in England for the period 2011-2020.

Results: The study covered a population of 19.4 million women over 30 years of age, attending 6,660 GP practices and being provided with 33.7 million prescriptions of LT4 and LT3 at a total cost of $£ 90$ million/year. Overall, $0.5 \%$ of levothyroxine treated patients continue to receive liothyronine. All Clinical Commission Groups (CCGs) in England continue to have at least one liothyronine prescribing practice and $48.5 \%$ of English general practices prescribed liothyronine in 2019-2020. Factors strongly influencing more levothyroxine prescribing (model accounted for $62 \%$ of variance) were the CCG to which the practice belonged and the proportion of people with diabetes registered on the practice list plus antidepressant prescribing, with socioeconomic disadvantage associated with less levothyroxine prescribing. Whereas factors that were associated with increased levels of liothyronine prescribing (model accounted for $17 \%$ of variance), were antidepressant prescribing and \% of type 2 diabetes mellitus individuals achieving $\mathrm{HbA1c}$ control of $58 \mathrm{mmol} / \mathrm{mol}$ or less. Factors that were associated with reduced levels of liothyronine prescribing included smoking and higher obesity rates.

Conclusion: In spite of strenuous attempts to limit prescribing of liothyronine in general practice a significant number of patients continue to receive this therapy, although there is significant geographical variation in the prescribing of this as for levothyroxine, with specific general practice and CCG-related factors influencing prescribing of both levothyroxine and liothyronine across England.
\end{abstract}




\section{1 | INTRODUCTION}

Primary hypothyroidism affects $2 \%-5 \%$ of the general population and is predominantly managed in the community. ${ }^{1}$ The majority of individuals with hypothyroidism are effectively treated with levothyroxine (LT4), but a proportion of patients suffer persistent symptoms, despite achieving biochemical control with levels of free thyroxine (FT4) and thyroid-stimulating hormone (TSH) within the laboratory reference ranges. ${ }^{2}$ Some patients who remain dissatisfied with LT4 therapy report improved well-being when prescribed combination therapy with liothyronine (LT3) and LT4. LT3 represents the synthetic form of the metabolically active thyroid hormone and was originally widely prescribed when synthetic thyroid hormones first replaced animal thyroid extracts in the 1950s. However, LT4 monotherapy has since prevailed as the treatment of choice for hypothyroidism because of its more favourable pharmacokinetic profile and once daily dosing schedule, coupled with the failure of randomised controlled trials to show superiority of combination therapy over LT4 alone. Furthermore, early clinical studies used unduly high doses of LT3 that sometimes resulted in unpleasant adverse effects from iatrogenic thyrotoxicosis. ${ }^{3}$

Accordingly, existing clinical guidelines do not support the routine use of LT3 in the management of hypothyroidism. ${ }^{4-6}$ The 2016 British Thyroid Association (BTA) position statement recommends that a trial of combination therapy can be considered in patients who unambiguously do not derive symptomatic benefit from LT4 alone, ${ }^{6}$ a position that is broadly consistent with the guidelines of the European and American Thyroid Associations. ${ }^{4,5}$ In the UK, LT3 prescribing has additionally been restricted by serial price increases following transition from the proprietary to the generic product in 2007 . $^{7}$ Cost considerations have in recent years prompted a series of local prescribing policies aimed at curtailing LT3 prescribing. In the wake of these policies, an analysis by Taylor et al $^{1}$ noted a substantial fall in LT3 use in England, a trend that varied geographically and was more pronounced in economically deprived areas. However, the drivers of thyroid hormone prescribing at practice level and the extent of prescribing variation for both LT4 and LT3 are unclear. In the present study, we evaluated geographical variation in LT4 and LT3 prescribing at general practice level in England and examined the factors associated with prescribing variation.

\section{METHODS}

\section{1 | Data sources}

We used a series of NHS general practice datasets to analyse thyroid hormone prescriptions at general practice level in England for the period 2019-2020. The study was conducted on data from the National Health Service (NHS) operational year April 2019-Mar 2020 , around which data is normally collated.

\section{What's known}

- Recent prescribing policies across the United Kingdom have imposed significant restrictions on liothyronine prescribing in general practice driven by the prohibitive costs and uncertain benefits of liothyronine in the management of hypothyroidism.

- However, the impact of these policies on liothyronine usage and costs are still unclear.

\section{What's new}

- In spite of strenuous attempts to limit prescribing of liothyronine in general practice, a significant number of patients continue to receive this therapy, although there is significant geographical variation in the prescribing of this, as for levothyroxine with general practice and clinical commissioning group (CCG) level factors a significant determinant.

Information on practice populations and patient distribution by age and sex was obtained from the General Practice registration dataset. ${ }^{7}$ This dataset contains a record of all registered patients in GP practices in England broken down by age-bands and sex within Clinical Commissioning Group (CCG) areas. In addition, we collated data from the NHS general practice workforce statistics dataset comprising information on staff numbers including GPs, nurses and other clinical and non-clinical staff working in general practices in England. ${ }^{8}$ The Quality Outcome Frameworks dataset was used to document chronic disease prevalence, care quality indicators, as well as social deprivation measures and urban/rural location of the general practice. ${ }^{9}$ We also extracted practice level data from the NHS General practice patient survey on rates of patient satisfaction and confidence in chronic disease management as well as ethnicity data for each practice. ${ }^{10}$

Medication use (LT4, LT3 and antidepressants) was obtained from published practice-level monthly prescriptions issued by the NHS Business Service Authority. Prescriptions were extracted by dose and British National Formulary (BNF) $\operatorname{code}^{7}$ and quantified according to the Defined Daily Dose (DDD). ${ }^{11}$ DDD is a standard method of comparing doses of a given medication and is taken as the average maintenance dose per day of a drug administered for its main indication in adults. ${ }^{11}$ The amount of active agent was converted to defined daily doses by applying the levels given in the World Health Organisation and Anatomical Therapeutic Chemical (WHO/ATC) classification. ${ }^{11}$ For LT3 which is most often used in combination with levothyroxine, an adjusted dose of $20 \mathrm{mcg} /$ day was applied and for LT4 $100 \mathrm{mcg} /$ day was used. All the data used in the analyses presented are publicly available and can be made available on request from $\mathrm{MS}$, co-author. 
FIGURE 1 Variation in prescribing by general practices in England in 2019/2020 for levothyroxine (blue line) and for liothyrinone (orange line). The left hand $y$-axis is the percentage of women aged $>30$ years on levothyroxine, and the right hand $y$-axis is the percentage of people on thyroid replacement treatment taking liothyronine. ADDD, annual defined daily dose

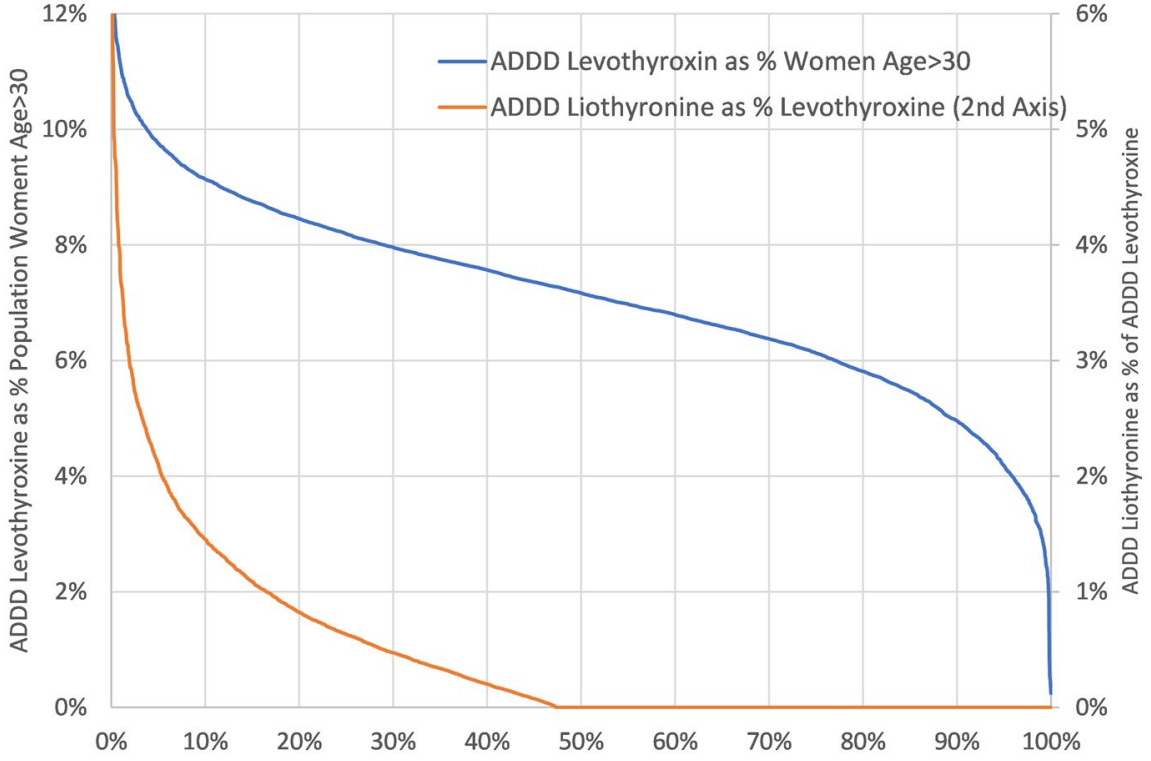

\subsection{Data analysis}

As the prevalence of hypothyroidism is higher in women, we calibrated prescribing of thyroid hormone replacement against the number of women in each general practice older than 30 years. In other words, the number of prescriptions as DDD was normalised for comparison between general practices by the number of women aged over 30 years old ${ }^{12}$ as this $38 \%$ of the population contains $85 \%$ of the patients with hypothyroidism. ${ }^{13}$ The gender and age mix for each practice were taken from the population data at general practice level. A multivariate regression model was used to identify the possible drivers of LT4 and LT3 prescribing. The outcome variables were (a) the amount of LT4 prescribed as a percentage of women aged $>30$ years, and (b) the amount of LT3 prescribed as a percentage of LT4 prescriptions.

The factors included in the model were as follows: (1) the local population characteristics (age, gender, ethnicity, social deprivation, location, urban vs rural, north vs south, east vs west); (2) the chronic disease burden of the population (rates of hypertension, diabetes, chronic obstructive pulmonary disease (COPD), asthma, cancer, depression and antidepressant prescription); (3) the general practitioner characteristics (age, gender, country of qualification); (4) general practice service performance based on levels of glycosylated haemoglobin $\mathrm{HbA1c}$ control reported in the national diabetes audit (NDA); and (5) the patient survey feedback regarding service satisfaction and patient confidence in managing their own long-term conditions.

The stepwise regression was first run with the all the local GP practice factors and then to establish the effect of the CCG. The local average CCG value for each prescribing variable was added as an additional factor for each practice into the stepwise regression to determine how much of the variation in local practices could be explained by their local CCG average for LT4 and LT3 prescribing. The difference in $r^{2}$ and standardised beta value for the CCG average was an indicator of the size of impact of the CCG on the model.
All analyses were conducted on 64 bit excel with power pivot and Analyse-it add in (Microsoft EXCEL). $X^{2}$ test was used to compare proportions. A $P$ value $<.05$ was considered significant.

\section{3 | RESULTS}

The study covered a population of 19.4 million women over 30 years of age, attending 6660 GP practices and being provided with 33.7 million prescriptions of LT4 and LT3 at a total cost of $£ 90$ million/ year.

\section{1 | Variation in LT4 and LT3 prescribing (Figure 1)}

In England, there are 135 local clinical commissioning groups of different population sizes. There was some variation in the identification and treatment of hypothyroidism with LT4 across different CCGs: the median was $7.0 \%$ of the population of women age $>30$ years. The lowest decile region was $5.5 \%$ while the highest decile was $8.3 \%$ of women $>30$ years old (factorial variation of 1.5 ). Variation in use of LT3 was higher. The median was $0.4 \%$ of those being treated with Levothyroxine. The lowest decile was $0.1 \%$ while the highest decile was $1.4 \%$ of those treated with LT4 (factorial variation of 14.0) (Figure 1). All CCGs had at least one LT3 prescribing practice, with $51.5 \%$ of general practices not prescribing any LT3.

\subsection{Geographical variation by CCG (Figure 2)}

There was a significant geographical variation across CCGs in England in rates of both LT4 and LT3 prescribing-adjusted for the proportion of women over the age of 30 in each CCG. In some areas such as the South-West, Herefordshire and Lincolnshire, higher prescribing of LT4 mapped to higher LT4 prescribing. In other areas such 
TAB LE 1 North vs South difference in LT4 and LT3 prescribing by CCG, described according to the number of CCGs in the lowest tertile of LT4 and LT3 prescribing

\begin{tabular}{|lll} 
& $\begin{array}{l}\text { North } \\
(\text { Latitude } \\
>\mathbf{5 2 . 6}\end{array}$ & $\begin{array}{l}\text { South } \\
(\text { Latitude } \\
\left.<=52.6^{\circ}\right)\end{array}$ \\
\hline $\begin{array}{l}\text { Number CCGs in Lowest Tertile for } \\
\text { Levothyroxine as \% Women }>30\end{array}$ & 16 & 29 \\
\hline $\begin{array}{l}\text { Number CCGs in Lowest Tertile for } \\
\text { Liothyronine \% Levothyroxine }\end{array}$ & 30 & 15 \\
\hline
\end{tabular}

as North Cumbria and County Durham, there was relatively high prescribing of LT4 but not LT3. Conversely in some areas such as Cheshire and Kent and Medway there was relatively high LT3 prescribing and lower prescribing of LT4.

Overall there are more CCGs in the North of England (defined as a latitude more northerly than 52.6 degrees north) in the lowest tertile of LT3 prescribing, $\mathrm{X}^{2} 3.4, P=.008$ (Table 1 ).

\section{3 | Regression modelling}

\subsection{1 | Levothyroxine prescribing (Figure 3)}

For local levels of levothyroxine excluding the effects of CCG guidance, the stepwise regression analysis could explain $54 \%$ of the variation between practices. When CCG average for ADDD levothyroxine as percentage of population women age $>30$ years was included as a factor, the regression model could explain $62 \%$ of the variation between general practices, the CCG component having a standardised beta of 0.38 and so the strongest impact. Other factors related to more LT4 prescribing were the proportion of older women in the general practice, the proportion of people registered with diabetes and chronic obstructive pulmonary disease at a general practice and the proportion of older general practitioners in the practice. A significant factor positively associated with more levothyroxine prescribing was the rate of antidepressant prescribing. Factors associated with less prescribing of LT4 included a higher proportion of people with significant social disadvantage, higher smoking rates and a higher proportion of people of black and ethnic minority (BME) ethnicity. General practices relatively more northerly in location tended to prescribe less levothyroxine.

\subsection{2 | Liothyronine prescribing (Figure 4)}

For local levels of LT3 prescribing, we considered all practices including those that prescribed none. The base analysis of local factors could only explain $6 \%$ of the variation between practices, however, by including the CCG average value effect, the stepwise regression analysis could explain $17 \%$ of the variation between practices, with the CCG component having a standardised beta of 0.34 . Other factors that were associated with increased levels of LT3 prescribing were rates of antidepressant prescribing and percentage of type 2 diabetes mellitus individuals achieving $\mathrm{HbA} 1 \mathrm{c}$ control of $58 \mathrm{mmol} /$ mol or less. Factors that were associated with reduced levels of LT3 prescribing included smoking and obesity rates and diabetes prevalence on the practice list.

\subsection{3 | Comparison of factors related to levothyroxine and liothyronine prescribing}

The main discretionary drivers of local thyroid prescribing for both levothyroxine and liothyronine were local CCG guidance, and practice use of antidepressant. However the impact of CCG guidance on liothyronine prescribing was much greater than for levothyroxine with tripling of the $r^{2}$. Specifically, this was much higher than for levothyroxine where $r^{2}$ increased by $20 \%$ when the CCG factor was included.

\subsection{4 | Year on year prescribing}

The $\mathrm{R}^{2}$ value for the factors relating to change in year on year prescribing for levothyroxine (6\%) and liothyronine (2\%) were low, indicating that the factors that we have access to (including which CCG they belong to) do not relate to difference in change in prescribing year on year, between practices (data not shown).

\section{4 | DISCUSSION}

Undetected hypothyroidism causes significant morbidity and may be complicated by cardiovascular disease, lipid disorders and neurocognitive impairment. In pregnancy, uncorrected maternal hypothyroidism increases risk of fetal loss, while neglected disease in the elderly may culminate in life-threatening metabolic decompensation. Furthermore, there remains a subset of individuals who report reduced quality of life with health needs that are not met with LT4. Despite a spate of recent guidelines and prescribing policies, the real-world approach to thyroid hormone replacement remains inconsistent and driven by factors that are still unclear. Here, we have evaluated variation in LT4 and LT3 prescribing across general practices in England and determined factors that influence prescribing.

We found significant variation in the use of LT3 and LT4 with a higher degree of variation seen with LT3 prescribing. Although all CCGs had at least one LT3 prescribing practice, about half of practices did not prescribe any LT3. The regression analysis indicated that the CCG that a general practice belongs to has the greatest influence on LT4 and LT3 prescribing. Other factors related to increased LT4 prescribing were the proportion of people registered with diabetes and chronic obstructive pulmonary disease at a general practice and rates of antidepressant prescribing. Interestingly, older general practitioners tended to prescribe more LT4. Factors associated with 
less LT4 prescribing included the proportion of people with obesity and of people with significant socioeconomic deprivation. For LT3, factors that were associated with increased prescribing were antidepressant use and the percentage of individuals with type 2 diabetes achieving $\mathrm{HbA} 1 \mathrm{c}$ control of $58 \mathrm{mmol} / \mathrm{mol}$ or less, whereas obesity, diabetes and smoking were associated with reduced prescribing.
In spite of strenuous attempts to limit LT3 prescribing in general practice, our findings show that a significant number of doctors continue to prescribe LT3. In England priorities for primary care are set by the local CCGs of which there are 135 of different sizes. Notably, all CCGs had at least one LT3 prescribing practice, suggesting a continued need for LT3 whether driven by patients or

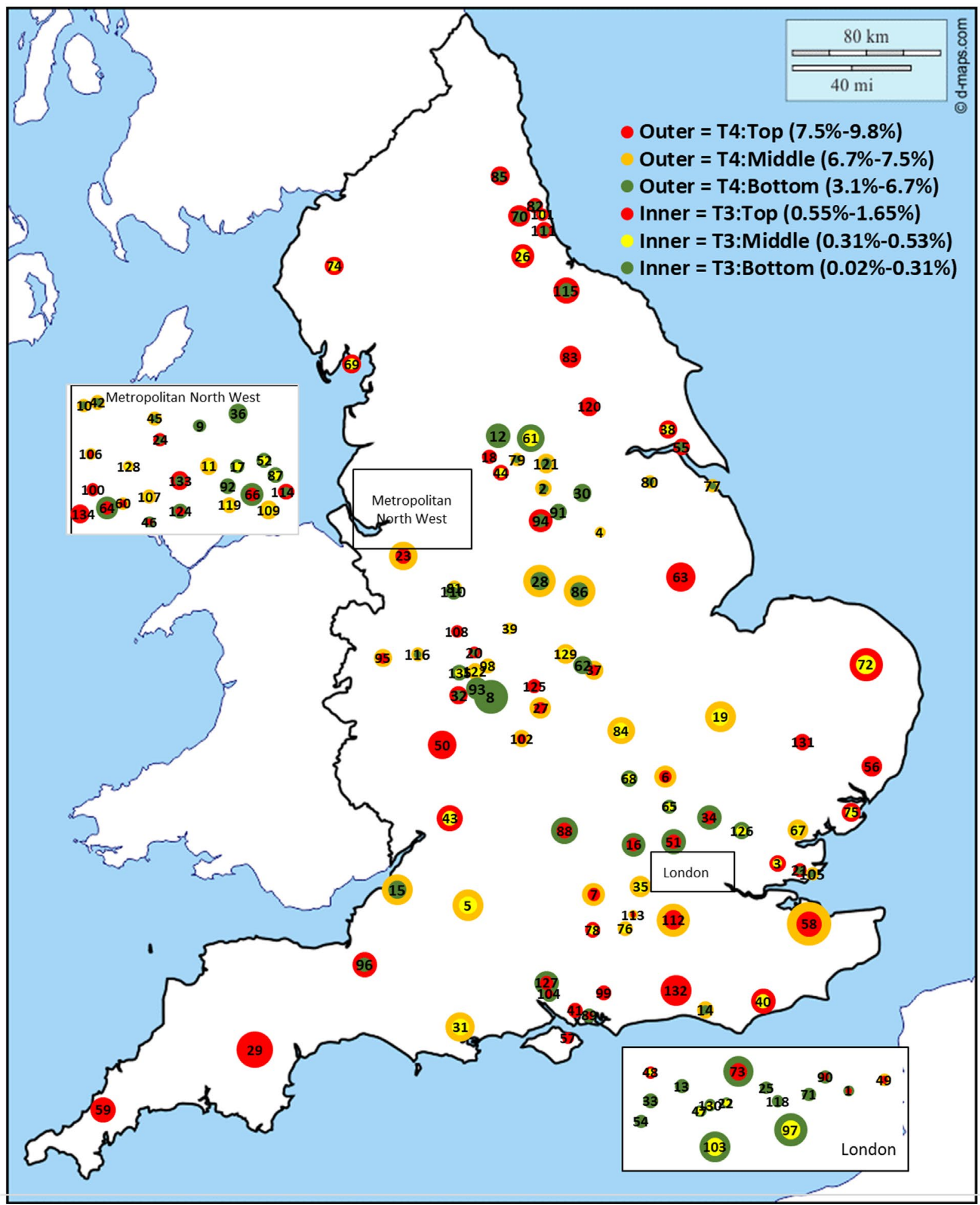

FIGURE 2 (A) Map of Variation in levothyroxine and liothyronine prescribing in England by CCG. (B) The key to the England CCG map with each numbered CCG described 


\begin{tabular}{|c|c|c|c|c|c|c|c|}
\hline & Women & ADDD & ADDD & & Women & ADDD & ADDD \\
\hline CCG & Age $>30$ & $\mathrm{~T} 4$ & T3 & CCG & Age $>30$ & $\mathrm{~T} 4$ & T3 \\
\hline 1 BARKING AND DAGENHAM & 62,646 & 3,222 & 23 & 69 MORECAMBE BAY & 117,695 & 9,150 & 37 \\
\hline 2 BARNSLEY & 87,640 & 6,058 & 13 & 70 NEWCASTLE GATESHEAD & 157,221 & 12,734 & 10 \\
\hline 3 BASILDON AND BRENTWOOD & 94,087 & 7,744 & 32 & 71 NEWHAM & 109,492 & 5,127 & 3 \\
\hline 4 BASSETLAW & 40,766 & 2,725 & 10 & 72 NORFOLK AND WAVENEY & 370,040 & 31,745 & 120 \\
\hline 5 BATH, NE SOMERSET, SWINDON AND WILTS & 323,835 & 22,304 & 110 & 73 NORTH CENTRAL LONDON & 516,979 & 27,044 & 153 \\
\hline 6 BEDFORDSHIRE & 162,642 & 11,815 & 71 & 74 NORTH CUMBRIA & 114,571 & 10,056 & 35 \\
\hline 7 BERKSHIRE WEST & 175,041 & 12,979 & 111 & 75 NORTH EAST ESSEX & 121,302 & 11,839 & 60 \\
\hline 8 BIRMINGHAM AND SOLIHULL & 392,267 & 24,533 & 55 & 76 NORTH EAST HAMPSHIRE AND FARNHAM & 77,411 & 5,376 & 25 \\
\hline 9 BLACKBURN WITH DARWEN & 52,930 & 3,355 & 2 & 77 NORTH EAST LINCOLNSHIRE & 56,477 & 4,214 & 13 \\
\hline 10 BLACKPOOL & 57,827 & 3,876 & 11 & 78 NORTH HAMPSHIRE & 77,809 & 5,977 & 27 \\
\hline 11 BOLTON & 97,936 & 7,163 & 30 & 79 NORTH KIRKLEES & 60,064 & 4,309 & 4 \\
\hline 12 BRADFORD DISTRICT AND CRAVEN & 193,997 & 12,185 & 36 & 80 NORTH LINCOLNSHIRE & 61,390 & 4,496 & 9 \\
\hline 13 BRENT & 117,559 & 6,144 & 8 & 81 NORTH STAFFORDSHIRE & 74,241 & 5,255 & 20 \\
\hline 14 BRIGHTON AND HOVE & 97,157 & 6,894 & 1 & 82 NORTH TYNESIDE & 77,955 & 6,290 & 18 \\
\hline 15 BRISTOL, N. SOMERSET AND S. GLOUCS & 325,082 & 23,114 & 38 & 83 NORTH YORKSHIRE & 156,101 & 12,997 & 138 \\
\hline 16 BUCKINGHAMSHIRE & 189,826 & 11,427 & 189 & 84 NORTHAMPTONSHIRE & 253,671 & 16,973 & 83 \\
\hline 17 BURY & 67,253 & 4,121 & 17 & 85 NORTHUMBERLAND & 119,542 & 10,087 & 22 \\
\hline 18 CALDERDALE & 73,492 & 6,673 & 40 & 86 NOTTINGHAM AND NOTTINGHAMSHIRE & 333,199 & 22,929 & 36 \\
\hline 19 CAMBRIDGESHIRE AND PETERBOROUGH & 311,141 & 22,222 & 109 & 87 OLDHAM & 78,947 & 4,572 & 23 \\
\hline 20 CANNOCK CHASE & 45,746 & 3,615 & 11 & 88 OXFORDSHIRE & 242,527 & 14,820 & 141 \\
\hline 21 CASTLE POINT AND ROCHFORD & 65,467 & 5,329 & 10 & 89 PORTSMOUTH & 64,196 & 4,187 & 34 \\
\hline 22 CENTRAL LONDON (WESTMINSTER) & 68,039 & 3,127 & 12 & 90 REDBRIDGE & 100,633 & 6,028 & 45 \\
\hline 23 CHESHIRE & 263,436 & 17,683 & 117 & 91 ROTHERHAM & 87,354 & 5,417 & 6 \\
\hline 24 CHORLEY AND SOUTH RIBBLE & 61,031 & 4,641 & 9 & 92 SALFORD & 79,838 & 5,332 & 13 \\
\hline 25 CITY AND HACKNEY & 96,871 & 3,023 & 9 & 93 SANDWELL AND WEST BIRMINGHAM & 161,453 & 9,975 & 15 \\
\hline 26 COUNTY DURHAM & 185,528 & 14,316 & 64 & 94 SHEFFIELD & 179,520 & 14,319 & 26 \\
\hline 27 COVENTRY AND RUGBY & 151,775 & 10,290 & 98 & 95 SHROPSHIRE & 113,318 & 8,228 & 69 \\
\hline 28 DERBY AND DERBYSHIRE & 355,469 & 24,433 & 35 & 96 SOMERSET & 206,069 & 16,076 & 17 \\
\hline 29 DEVON & 435,522 & 34,389 & 273 & 97 SOUTH EAST LONDON & 627,453 & 31,438 & 108 \\
\hline 30 DONCASTER & 106,763 & 6,899 & 19 & 98 SOUTH EAST STAFFORDSHIRE AND SEISDON & 73,530 & 5,161 & 27 \\
\hline 31 DORSET & 285,607 & 19,380 & 74 & 99 SOUTH EASTERN HAMPSHIRE & 77,366 & 5,970 & 82 \\
\hline 32 DUDLEY & 109,520 & 8,460 & 8 & 100 SOUTH SEFTON & 53,469 & 4,172 & 32 \\
\hline 33 EALING & 133,964 & 7,708 & 15 & 101 SOUTH TYNESIDE & 53,569 & 4,940 & 16 \\
\hline 34 EAST AND NORTH HERTFORDSHIRE & 196,313 & 11,973 & 66 & 102 SOUTH WARWICKSHIRE & 102,499 & 7,462 & 53 \\
\hline 35 EAST BERKSHIRE & 146,561 & 10,861 & 34 & 103 SOUTH WEST LONDON & 537,319 & 30,659 & 138 \\
\hline 36 EAST LANCASHIRE & 123,343 & 7,652 & 5 & 104 SOUTHAMPTON & 80,669 & 4,848 & 27 \\
\hline 37 EAST LEICESTERSHIRE AND RUTLAND & 118,256 & 7,976 & 58 & 105 SOUTHEND & 63,395 & 4,707 & 13 \\
\hline 38 EAST RIDING OF YORKSHIRE & 111,831 & 9,785 & 50 & 106 SOUTHPORT AND FORMBY & 46,346 & 3,427 & 28 \\
\hline 39 EAST STAFFORDSHIRE & 48,008 & 3,569 & 17 & 107 ST HELENS & 67,407 & 4,952 & 24 \\
\hline 40 EAST SUSSEX & 202,868 & 18,347 & 71 & 108 STAFFORD AND SURROUNDS & 52,344 & 4,079 & 36 \\
\hline 41 FAREHAM AND GOSPORT & 73,089 & 5,720 & 59 & 109 STOCKPORT & 107,502 & 7,682 & 31 \\
\hline 42 FYLDE AND WYRE & 66,319 & 4,678 & 12 & 110 STOKE ON TRENT & 91,962 & 6,120 & 11 \\
\hline 43 GLOUCESTERSHIRE & 225,279 & 17,049 & 90 & 111 SUNDERLAND & 93,974 & 8,266 & 21 \\
\hline 44 GREATER HUDDERSFIELD & 79,608 & 7,395 & 27 & 112 SURREY HEARTLANDS & 370,079 & 26,535 & 211 \\
\hline 45 GREATER PRESTON & 65,455 & 4,504 & 4 & 113 SURREY HEATH & 33,519 & 2,353 & 13 \\
\hline 46 HALTON & 43,533 & 2,868 & 19 & 114 TAMESIDE AND GLOSSOP & 81,801 & 6,159 & 19 \\
\hline 47 HAMMERSMITH AND FULHAM & 83,265 & 3,009 & 10 & 115 TEES VALLEY & 231,951 & 19,337 & 56 \\
\hline 48 HARROW & 86,958 & 6,804 & 29 & 116 TELFORD AND WREKIN & 61,392 & 4,174 & 3 \\
\hline 49 HAVERING & 94,126 & 6,333 & 43 & 117 THURROCK & 56,500 & 4,319 & 17 \\
\hline 50 HEREFORDSHIRE AND WORCESTERSHIRE & 279,545 & 22,303 & 211 & 118 TOWER HAMLETS & 86,408 & 4,231 & 7 \\
\hline 51 HERTS VALLEYS & 209,701 & 13,701 & 75 & 119 TRAFFORD & 81,055 & 5,587 & 26 \\
\hline 52 HEYWOOD, MIDDLETON AND ROCHDALE & 73,943 & 4,253 & 19 & 120 VALE OF YORK & 120,199 & 9,886 & 101 \\
\hline 53 HILLINGDON & 97,911 & 5,943 & 6 & 121 WAKEFIELD & 126,505 & 9,336 & 9 \\
\hline 54 HOUNSLOW & 100,189 & 5,576 & 10 & 122 WALSALL & 90,842 & 6,787 & 29 \\
\hline 55 HULL & 91,793 & 7,584 & 8 & 123 WALTHAM FOREST & 96,368 & 4,453 & 30 \\
\hline 56 IPSWICH AND EAST SUFFOLK & 140,785 & 11,440 & 68 & 124 WARRINGTON & 73,801 & 4,118 & 43 \\
\hline 57 ISLE OF WIGHT & 47,592 & 3,894 & 31 & 125 WARWICKSHIRE NORTH & 65,002 & 5,626 & 47 \\
\hline 58 KENT AND MEDWAY & 636,552 & 46,427 & 337 & 126 WEST ESSEX & 105,699 & 6,685 & 21 \\
\hline 59 KERNOW & 209,492 & 16,733 & 205 & 127 WEST HAMPSHIRE & 193,632 & 12,746 & 162 \\
\hline 60 KNOWSLEY & 54,520 & 3,803 & 27 & 128 WEST LANCASHIRE & 38,659 & 2,868 & 13 \\
\hline 61 LEEDS & 262,713 & 17,518 & 93 & 129 WEST LEICESTERSHIRE & 130,976 & 8,911 & 47 \\
\hline 62 LEICESTER CITY & 114,465 & 7,451 & 8 & 130 WEST LONDON & 86,427 & 3,434 & 14 \\
\hline 63 LINCOLNSHIRE & 274,465 & 20,713 & 131 & 131 WEST SUFFOLK & 90,236 & 7,506 & 48 \\
\hline 64 LIVERPOOL & 162,753 & 9,857 & 118 & 132 WEST SUSSEX & 318,810 & 24,156 & 136 \\
\hline 65 LUTON & 67,039 & 3,810 & 12 & 133 WIGAN BOROUGH & 110,327 & 8,417 & 19 \\
\hline 66 MANCHESTER & 171,435 & 9,067 & 51 & 134 WIRRAL & 113,975 & 8,651 & 63 \\
\hline 67 MID ESSEX & 135,989 & 9,591 & 45 & 135 WOLVERHAMPTON & 89,222 & 5,609 & 22 \\
\hline 68 MILTON KEYNES & 93,309 & 4,945 & 24 & & & & \\
\hline
\end{tabular}

FIGURE 2 Continued

their clinicians. Although cost considerations have led to prescribing policies designed to reduce LT3 prescription, the continued use of LT3 may have been encouraged by various sets of guidance published in the last decade ${ }^{4-6}$ that now allow LT3 prescriptions in carefully selected individuals. Rates of LT4 prescribing on the other hand are influenced by differing views on the laboratory TSH thresholds for LT4 initiation. ${ }^{13}$ Although these thresholds have progressively reduced over the years, ${ }^{14}$ our results suggest that there is a significant variation with respect to screening and treatment initiation in patients with hypothyroidism. The influence 


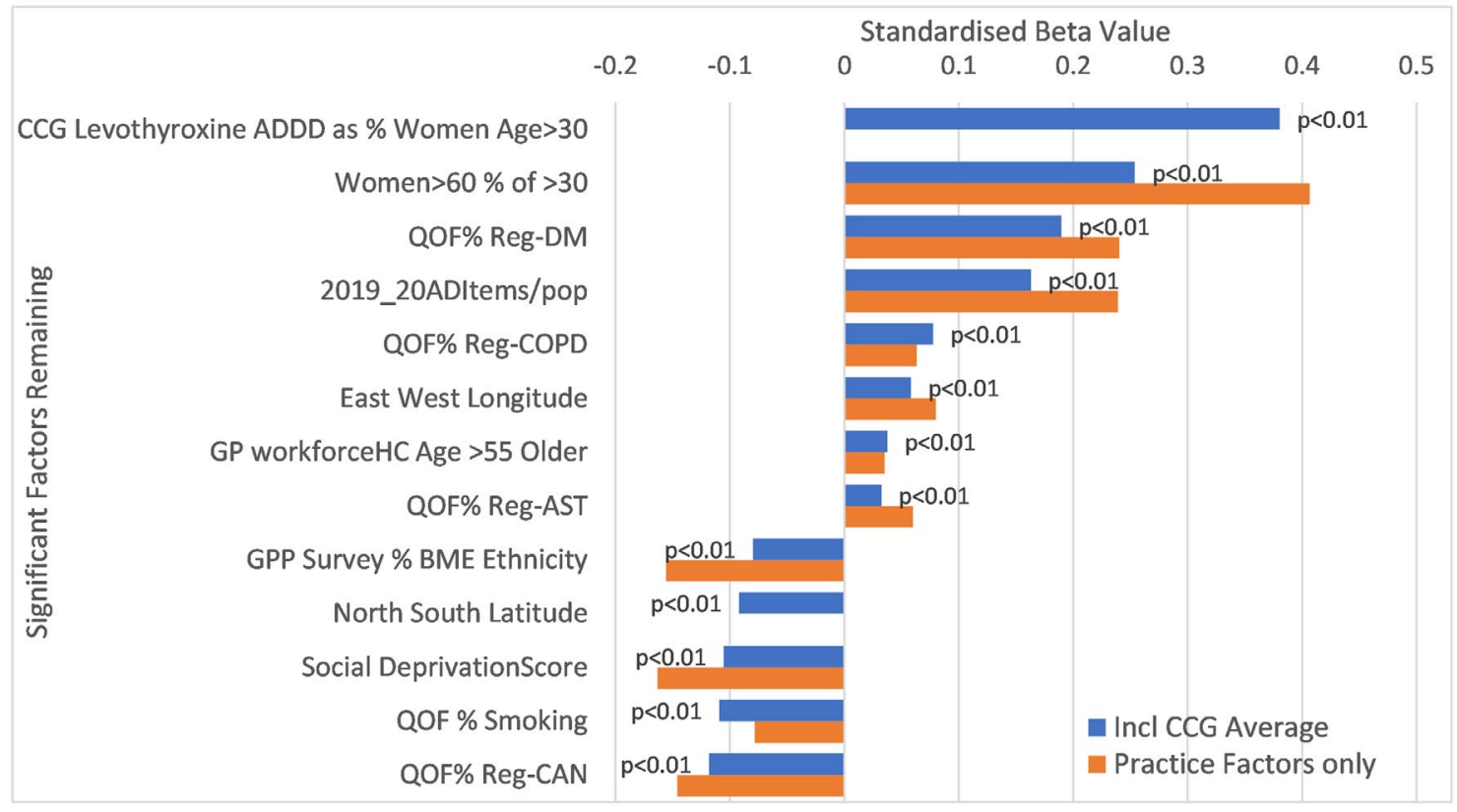

FIGURE 3 Factors independently linked with levothyroxine prescribing in England. ADDD, annual defined daily dose; AST, Asthma; BME, black and minority ethnicity; CAN, cancer; CCG, Clinical Commissioning Group; COPD, chronic obstructive pulmonary disease; DM, diabetes mellitus; GP workforce HC, General Practitioner Workforce Head Count; QOF, Quality Outcome Framework

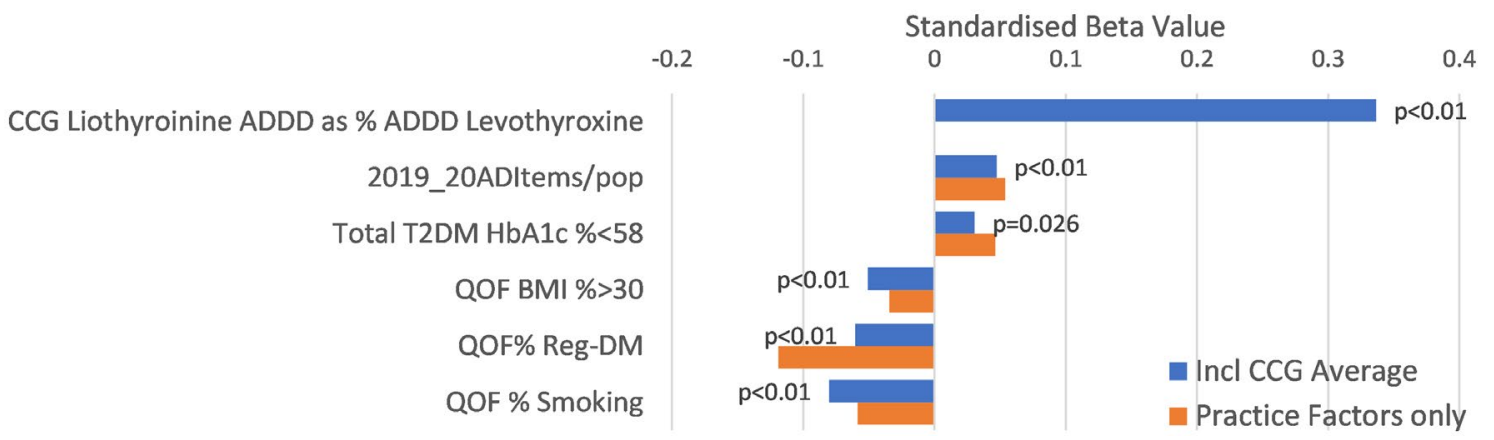

FIGURE 4 Factors independently linked with liothyronine prescribing in England: AD, antidepressant; BMI, body mass index; ADDD, annual defined daily dose; CCG, Clinical Commissioning Group; QOF, Quality Outcome Framework; T2DM, diabetes mellitus

of CCGs through local medicine management committees appear to play an over-riding role in the approach to both LT3 and LT4 prescribing.

The increased LT4 prescribing seen in association with comorbidities like diabetes, chronic obstructive pulmonary disease and depression may reflect frequent testing and diagnosis in these groups of patients due to their more frequent contact with general practice. The association of both LT4 and LT3 prescribing to rates of antidepressant prescribing may as alluded be a measure of how an individual general practice may be attuned to their practice population in relation to the realities of living with long-term conditions and their consequences. ${ }^{15}$ In addition, patients with depression are more likely to have frequent contacts with their practices and therefore more likely to be tested for unresolved symptoms. ${ }^{15}$ Reduced LT4 prescription was also seen with social deprivation, practices in more northern regions of England, and black and ethnic minority individuals suggesting inequalities in care access. Similar variations were reported by Taylor et al. ${ }^{1}$ Thus 50 years after the seminal paper by Taylor et al in 1970, ${ }^{16}$ the combination of LT4 and LT3 still finds favour with a good number of practitioners and many patients.

\section{1 | Strengths/Limitations}

A strength of this study is in the use of real-world general practice data collated at a national level, better to understand the factors influencing thyroid hormone prescribing across all CCGs in England. Although we have not looked at data from the other nations that make up the UK, our findings are likely to be applicable to the other parts of the UK and other parts of the world where there is a large differential between the costs of LT4 and LT3. Also we have not specifically evaluated the prescribing of NDT which is used by a small proportion of patients with hypothyroidism. 
The matter of longitudinal trends in prescribing LT4 and LT3 in England is the subject of a separate paper. ${ }^{17}$

\subsection{Conclusion}

There is significant geographical variation in the prescribing of LT4 and LT3 in general practice, The CCG where any general practice is located appears to be the over-riding influence on thyroid hormone prescribing with the influence much greater for LT3 than for LT4 prescribing.

\section{DISCLOSURES}

None of the co-authors has any conflict of interest in relation to the work presented here.

\section{DATA AVAILABILITY STATEMENT}

All the data used in the analyses presented is publically available and can be also made available from MS, co-author on application.

\section{ORCID}

Mike Stedman (iD https://orcid.org/0000-0002-0491-7823

Adrian H. Heald iD https://orcid.org/0000-0002-9537-4050

\section{REFERENCES}

1. Taylor PN, Albrecht D, Scholz A, et al. Global epidemiology of hyperthyroidism and hypothyroidism. Nat Rev Endocrinol. 2018;14:301-316.

2. Saravanan P, Chau WF, Roberts N, Vedhara K, Greenwood R, Dayan CM. Psychological well-being in patients on "adequate" doses of Ithyroxine: results of a large, controlled community-based questionnaire study. Clin Endocrinol (Oxf). 2002;57:577-578.

3. Smith RN, Taylor SA, Massey JC. Controlled clinical trial of combined triiodothyronine and thyroxine in the treatment of hypothyroidism. Br Med J. 1970;17:145-148.

4. Wiersinga WM, Duntas L, Fadeyev V, Nygaard B, Vanderpump MP. 2012 ETA guidelines: the use of L-T4 + L-T3 in the treatment of hypothyroidism. Eur Thyroid J. 2012;1:55-71.

5. Jonklaas J, Bianco AC, Bauer AJ, et al. American thyroid association task force on thyroid hormone replacement. Guidelines for the treatment of hypothyroidism: prepared by the American thyroid association task force on thyroid hormone replacement. Thyroid. 2014;24:1670-1751.

6. Okosieme O, Gilbert J, Abraham P, et al. Management of primary hypothyroidism: statement by the British Thyroid Association Executive Committee. Clin Endocrinol (Oxf). 2016;84:799-808.

7. https://digital.nhs.uk/data-and-information/publications/statistica I/practice-level-prescribing-data. Accessed October 1, 2020.

8. https://digital.nhs.uk/data-and-information/publications/statistica I/general-and-personal-medical-services. Accessed October 2, 2020.

9. https://qof.digital.nhs.uk/. Accessed October 1, 2020.

10. https://www.gp-patient.co.uk/. Accessed October 1, 2020.

11. WHO Collaborating Centre for Drug Statistics Methodology. Defined Daily Dose (DDD). ATC/DDD index. http://www.whocc. no/atc_ddd_index. Accessed October 3, 2020.

12. https://www.ons.gov.uk/peoplepopulationandcommunity/popul ationandmigration

13. Giorda CB, Carnà P, Romeo F, Costa G, Tartaglino B, Gnavi R. Prevalence, incidence and associated comorbidities of treated hypothyroidism: an update from a European population. Eur J Endocrinol. 2017;176:533-542.

14. Taylor PN, Iqbal A, Minassian C, et al. Falling threshold for treatment of borderline elevated thyrotropin levels-balancing benefits and risks: evidence from a large community-based study. JAMA Intern Med. 2014;174:32-39.

15. Heald AH, Stedman M, Davies M, Farman S, Taylor D, Bailey S, Gadsby R. Quantifying the impact of patient-practice relationship quality on the levels of the average annual antidepressant practice prescribing rate in primary care in England. Prim Care Companion CNS Disord. 2020;22.

16. Taylor S, Kapur M, Adie R. Combined thyroxine and triiodothyronine for thyroid replacement therapy. BMJ. 1970;2:270-271.

17. Stedman M, Taylor P, Premawardhana L, Okosieme O, Dayan C, Heald $\mathrm{AH}$. Trends in costs and prescribing for liothyronine and levothyroxine in England and wales 2011-2020. Clinical Endocrinology. 2021;94:980-989. https://doi.org/10.1111/cen.14414.

How to cite this article: Stedman M, Taylor P, Premawardhana L, Okosieme O, Dayan C, Heald AH. Liothyronine and levothyroxine prescribing in England: A comprehensive survey and evaluation. Int J Clin Pract. 2021;75:e14228. https://doi.org/10.1111/ijcp.14228 